\title{
Robust Tension Control of Strip for 5-Stand Tandem Cold Mills
}

\author{
Behrooz Shafiei, ${ }^{1}$ Mohsen Ekramian, ${ }^{2}$ and Khoshnam Shojaei ${ }^{3}$ \\ ${ }^{1}$ Department of Automation Engineering, Tandem Cold Rolling Mill, Mobarakeh Steel Company, Isfahan, Iran \\ ${ }^{2}$ Department of Electrical Engineering, Faculty of Engineering, University of Isfahan, Isfahan, Iran \\ ${ }^{3}$ Department of Electrical Engineering, Najafabad Branch, Islamic Azad University, Isfahan, Iran
}

Correspondence should be addressed to Behrooz Shafiei; bh_shmo@yahoo.com

Received 3 July 2014; Accepted 8 October 2014; Published 5 November 2014

Academic Editor: Xiao He

Copyright (C) 2014 Behrooz Shafiei et al. This is an open access article distributed under the Creative Commons Attribution License, which permits unrestricted use, distribution, and reproduction in any medium, provided the original work is properly cited.

\begin{abstract}
Tandem cold rolling process is a nonlinear complex system with external and internal uncertainties and significant disturbances. The improvement in the quality of the final output depends on the control strategy of centerline thickness and interstand tension. This paper focuses on interstand tension control problem in 5-stand tandem cold rolling mills. Tension dynamics can be described by a nominal model perturbed by parametric uncertainties. In order to overcome the model uncertainties and external disturbances, suboptimal $H_{\infty}$ and $\mu$ controllers are proposed and the Hankel-norm approximation is used to reduce the order of $\mu$ controller. The performance of the proposed controllers is demonstrated by some simulations.
\end{abstract}

\section{Introduction}

The production of cold rolled coils typically consists of separate processes such as annealing, pickling, cold rolling, and skin pass rolling. The cold rolling of strip is one of the most important processes in the areas of manufacturing and processing of metals. Tandem cold mill (TCM) is one type of cold rolling processes that strip thickness reduction is achieved with a number of nonreversing stands. The production of this process can be applied for various industries such as food packaging, automobile manufacturing, and home appliance $[1,2]$. Thus, the improvement and development of new technologies of rolling have become important for researchers, engineers, and manufacturers.

Tension control is one of the most important process parameters in tandem cold mill (TCM). Changing roll velocity stabilizes the interstand tension [3]. Interstand tension should be maintained at acceptable levels. Large transient variations in tension may result in a dramatic and physically damaging failure of the mill through looping, where the strip tension falls to zero, or tearing of the strip $[4,5]$.

Various advanced methods have been developed to analyze and control rolling mills [6-11]. Among the previous investigations, some notes focus on tension control problem in cold rolling mills $[12,13]$. There are numerous uncertainties and disturbances in the model of tandem cold rolling process [14]. Thus, the control strategy for cold rolling should be robust with respect to the uncertainties and disturbances. Linear quadratic control strategy $\left(\mathrm{H}_{2}\right)$ guarantees the optimality but it has weakness in the presence of uncertainties. The suboptimal $H_{\infty}$ method and $\mu$ synthesis/analysis method have been adopted as the robust techniques in many approaches and provide systematic design procedures of robust controllers for linear system $[3,15,16]$.

To promote tension control of cold rolling mills, two advanced robust control systems are proposed. First, a statespace description of full stands with parametric uncertainty is derived for tension system with 5-stand tandem mills. Taking into account the variation of strip thickness, Young's modulus, forward slip, and speed actuator time constant, the model of structured uncertainties is presented. In the next step, two robust controllers are designed by using suboptimal $H_{\infty}$ controller method and $\mu$ synthesis. The order of $\mu$ controller is too large and this makes it necessary to apply controller order reduction. Simulation results show that the $\mu$ robust controller and reduced-order controller have better robustness and disturbance attenuation performance than $H_{\infty}$ controller.

This paper is organized as follows. In Section 2, interstand tension and relations between its parameters are introduced. 


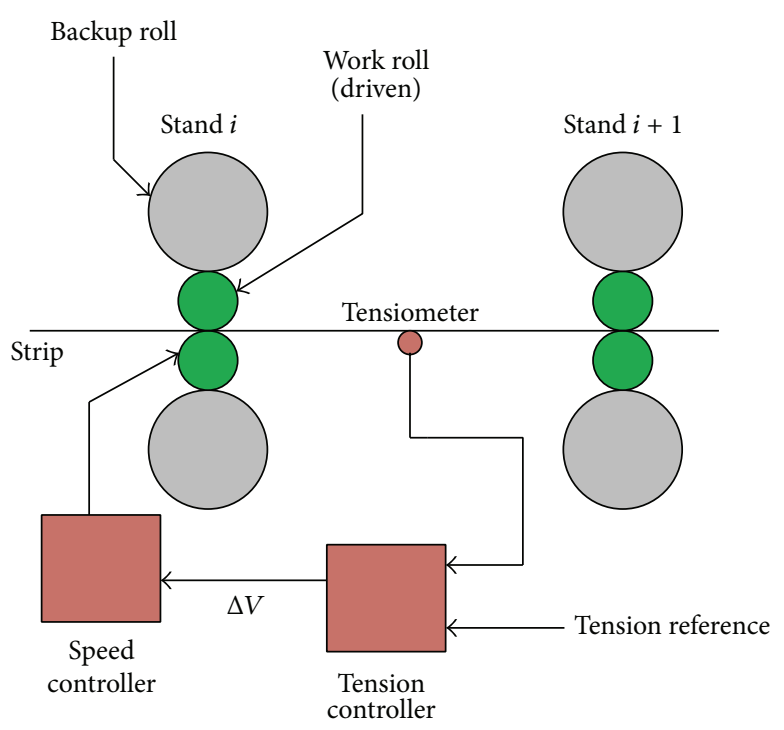

FIGURE 1: Schematic of conventional tension control for TCM.

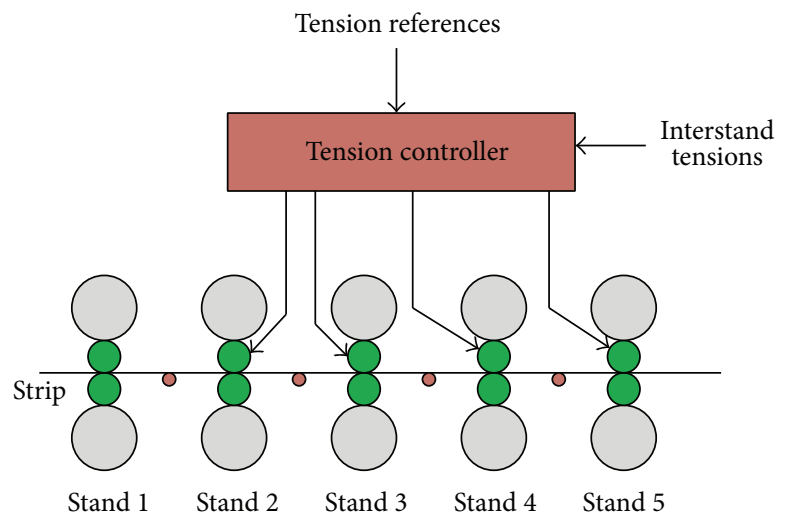

FIgURE 2: The structure of the advanced tension control system.

Then, a state-space description is derived for tension system and it is shown that the perturbation can be represented by parametric uncertainty. In Section 3, suboptimal $H_{\infty}$ control and $\mu$ synthesis method are applied to tension control problem, and then the order of $\mu$ controller is reduced. The Section 4 is devoted to comparing robust stability, robust performance, and time domain responses of robust controllers. Some simulation results are also given to show the proposed methods in the presence of model uncertainties and external disturbances. Finally, the concluding remarks are presented in Section 5.

\section{Interstand Strip Tension Overview}

In tandem cold mill (TCM), strip passes through individual pairs of work rolls. Each work roll is supported by a backup roll of a large diameter $[2,14]$. In order to achieve good tension control, tensiometer is the reliable instrument to measure the tension between stands. Figure 1 shows the conventional tension control by speed where subscript $i$ represents the mill stand number for $i$ th stand. The difference between the strip speed at the input to stand $i+1$ and the strip speed at the output of stand $i$ implies tension change.

The structure of conventional controllers is usually based on single-input-single-output (SISO) control loops which limits its capability for improvement. To overcome this problem and improvement in the performance of tension control, conventional methods are broken and two advanced tension control strategies based on robust strip tension are proposed. Figure 2 shows the structure of MIMO tension control system. First stand is chosen as a "pivot stand" and the speed of this stand is not trimmed.

In this section, a state-space description of the nominal interstand tension perturbed by parametric uncertainty is presented to be adopted in controller design.

2.1. Mathematical Model. To obtain the state-space and output equations for interstand tension, the theoretical system equations are introduced here [14]. Abbreviations section describes the symbols that appear in these equations. 


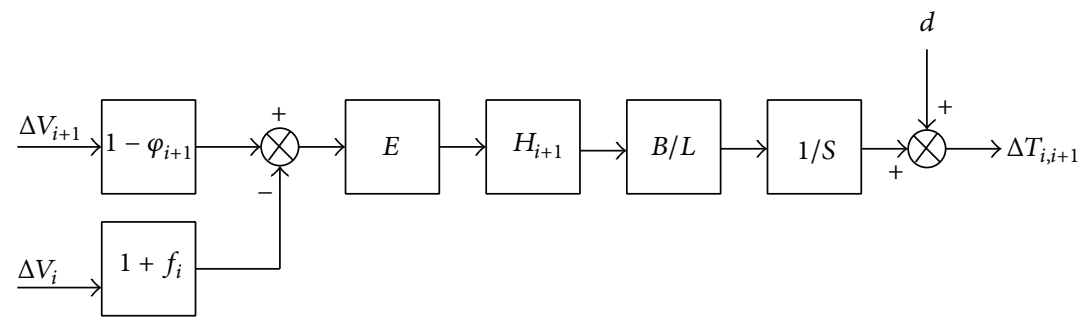

FIGURE 3: Block diagram of tension system between adjacent stands.

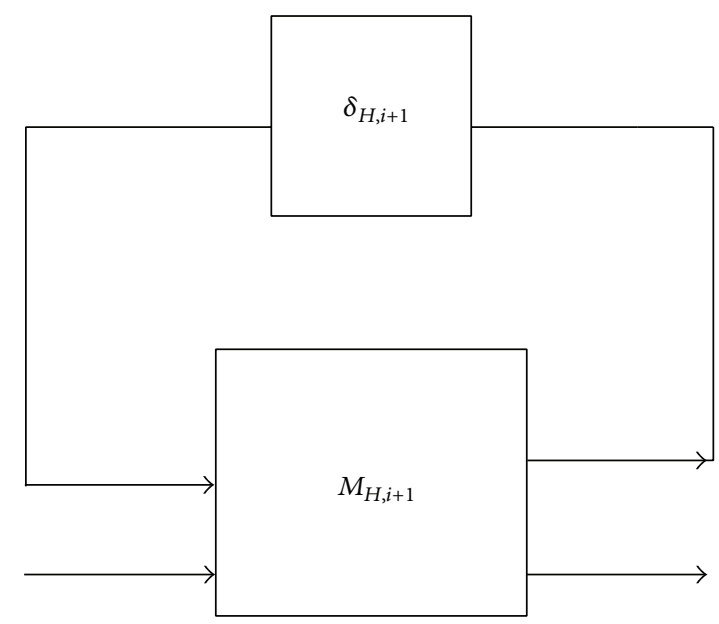

FIGURE 4: Representation of uncertain parameter $\left(H_{i+1}\right)$ as LFTs.

(1) Interstand tension is developed by applying Hooke's law to a length of strip between successive mill stands and is governed by the following dynamic:

$$
\frac{d \Delta\left(T_{i, i+1}\right)}{d t} \equiv \Delta \dot{T}_{i, i+1}=\frac{\mathrm{EBH}_{i+1}\left(V_{\mathrm{in}, i+1}-V_{\mathrm{out}, i}\right)}{L} .
$$

(2) During rolling, the work roll is elastically flattened. At the entry to work roll, the strip speed is less than the peripheral speed of the work roll, and at the exit of the work roll, speed is greater than the peripheral speed of the work roll. The forward slip ratio and the backward slip ratio are determined by the following.

(a) Forward slip ratio:

$$
f=\frac{V_{\text {out }}-V}{V} .
$$

(b) Backward slip ratio:

$$
\varphi=\frac{V-V_{\text {in }}}{V} .
$$

(3) The relationship among the entry and exit thickness and strip velocity at the entry and exit to stand is called volume continuity and is determined by the following equation:

$$
h_{\text {in }} \times V_{\text {in }}=h_{\text {out }} \times V_{\text {out }} .
$$

(4) The work roll drive equation is modeled (closed-loop) and is approximated in order one, based on typical data

$$
\dot{V}_{i}=\frac{U_{v, i}}{\tau_{v, i}}-\frac{V_{i}}{\tau_{v, i}} .
$$

Equations (1) to (3) are combined to yield the following equation:

$$
\Delta \dot{T}_{i, i+1}=\frac{\mathrm{EBH}_{i+1}}{L}\left(\left(1-\varphi_{i+1}\right) \Delta V_{i+1}-\left(1+f_{i}\right) \Delta V_{i}\right) .
$$

According to (6), the tension system between two stands is depicted in Figure 3.

2.2. Uncertainties in Modeling. Based on (5) and (6), variations of four coefficients $H_{i+1}, E, \varphi_{i}$, and $\tau_{v, i}$ are considered as parametric uncertainty. Parametric uncertainty is represented by variations of certain system parameters which may adversely affect the stability and performance of a control system. In Figure 3, the four constant blocks can be replaced by upper linear fractional transformation (LFT). For instance, $H_{i+1}$ may be represented as upper LFT in $P_{H, i+1}$ and $\delta_{H, i+1}\left(-1<\delta_{H, i+1}<1\right)$ and further $\bar{H}_{i+1}$ is the so-called nominal value of $H_{i+1}$. The LFT framework for $H_{i+1}$ depicts in Figure 4

$$
\begin{gathered}
H_{i+1}=\bar{H}_{i+1}\left(1+P_{H, i+1} \delta_{H, i+1}\right)=F_{u}\left(M_{H, i+1}, \delta_{H, i+1}\right), \\
M_{H, i+1}=\left[\begin{array}{cc}
0 & \bar{H}_{i+1} \\
P_{H, i+1} & \bar{H}_{i+1}
\end{array}\right] .
\end{gathered}
$$

Similarly, the other parameters can be represented as upper LFT in $\delta_{\eta, i+1}, \delta_{\tau_{v, i}}$, and $\delta_{E}$. It is supposed that $\eta=1-\varphi$ for simplification. The parameters of full stand tension system and their tolerances are given in Table 1 [13]. 
TABLE 1: Nominal values and their tolerance.

\begin{tabular}{lccc}
\hline Parameter & Nominal value & Unit & Uncertainty \\
\hline$E_{n}$ & $2.1 \times 10^{5}$ & $\mathrm{~N} / \mathrm{mm}^{2}$ & $\pm 10.0 \%$ \\
$T_{v n}$ & 0.1 & $\mathrm{~s}$ & $\pm 20.0 \%$ \\
$H_{2}$ & 1.35 & $\mathrm{~mm}$ & $\pm 5.0 \%$ \\
$H_{3}$ & 0.77 & $\mathrm{~mm}$ & $\pm 5.0 \%$ \\
$H_{4}$ & 0.5 & $\mathrm{~mm}$ & $\pm 5.0 \%$ \\
$H_{5}$ & 0.33 & $\mathrm{~mm}$ & $\pm 5.0 \%$ \\
$\varphi_{2}$ & 0.3 & - & $\pm 10.0 \%$ \\
$\varphi_{3}$ & 0.25 & - & $\pm 10.0 \%$ \\
$\varphi_{4}$ & 0.2 & - & $\pm 10.0 \%$ \\
$\varphi_{5}$ & 0.2 & - & $\pm 10.0 \%$ \\
$L$ & 4.5 & $\mathrm{~m}$ & 0 \\
$B$ & 1 & $\mathrm{~m}$ & 0 \\
\hline
\end{tabular}

2.3. State-Space Representation. Based on (4)-(6), the statespace description of tension system with 5-stand yields

$$
\begin{gathered}
X^{\prime}=A X+B_{1} U_{u}+B_{2} U, \\
Y_{u}=C_{1} X+D_{11} U_{u}+D_{12} U, \\
Y=C_{2} X+D_{21} U_{u}+D_{22} U .
\end{gathered}
$$

The state vector $X$, the control inputs $U$ and $U_{u}$, and the output vectors $Y$ and $Y_{u}$ are defined as

$$
\begin{gathered}
X=\left[\Delta V_{2}, \Delta \sigma_{1,2}, \Delta V_{3}, \Delta \sigma_{2,3}, \Delta V_{4}, \Delta \sigma_{3,4}, \Delta V_{5}, \Delta \sigma_{4,5}\right]^{\mathrm{T}}, \\
U=\left[\Delta U_{v, 2}, \Delta U_{v, 3}, \Delta U_{v, 4}, \Delta U_{v, 5}\right]^{\mathrm{T}}, \\
U_{u}=\left[U_{\tau_{v, 2}}, U_{\eta, 2}, U_{E, 2}, U_{H, 2}, U_{\tau_{v, 3}}, U_{\eta, 3}, U_{E, 3}, U_{H, 3},\right. \\
\left.U_{\tau_{v, 4}}, U_{\eta, 4}, U_{E, 4}, U_{H, 4}, U_{\tau_{v, 5}}, U_{\eta, 5}, U_{E, 5}, U_{H, 5}\right]^{\mathrm{T}}, \\
Y_{u}=\left[y_{\tau_{v, 2}}, y_{\eta, 2}, y_{E, 2}, y_{H, 2}, y_{\tau_{v, 3}}, y_{\eta, 3}, y_{E, 3}, y_{H, 3},\right. \\
\left.y_{\tau_{v, 4}}, y_{\eta, 4}, y_{E, 4}, y_{H, 4}, y_{\tau_{v, 5}}, y_{\eta, 5}, y_{E, 5}, y_{H, 5}\right]^{\mathrm{T}}, \\
Y=\left[\Delta T_{1,2}, \Delta T_{2,3}, \Delta T_{3,4}, \Delta T_{4,5}\right]^{\mathrm{T}} .
\end{gathered}
$$

$G_{\text {Ten }}$ denotes the input/output dynamics of the tension system, which takes into account the uncertainty of parameters. The state-space representation of $G_{\text {Ten }}$ is (the system matrices are presented in Appendix A)

$$
G_{\text {Ten }}=\left[\begin{array}{ccc}
A & B_{1} & B_{2} \\
C_{1} & D_{11} & D_{12} \\
C_{2} & D_{21} & D_{22}
\end{array}\right] .
$$

The uncertain behavior of the original system can be described by an upper LFT representation

$$
Y=F_{U}\left(G_{\mathrm{Ten}}, \Delta\right) U
$$

With diagonal uncertainty matrix $\Delta=\operatorname{diag}\left(\delta_{v, 2}, \delta_{\eta, 2}, \delta_{E, 2}\right.$, $\left.\delta_{H, 2}, \ldots, \delta_{v, 5}, \delta_{\eta, 5}, \delta_{E, 5}, \delta_{H, 5}\right)$, as shown in Figure 5. It should be noted that the unknown matrix $\Delta$ has a fixed structure and in general is a block diagonal. Such uncertainty is called structured uncertainty.

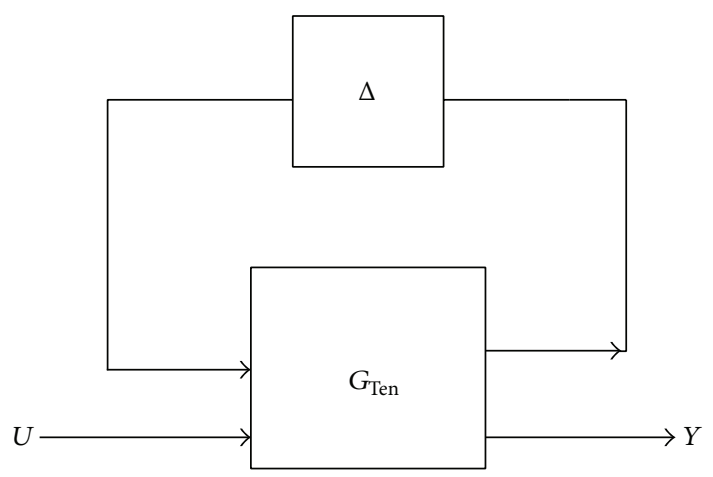

FIGURE 5: LFT representation of the tension system with uncertainties.

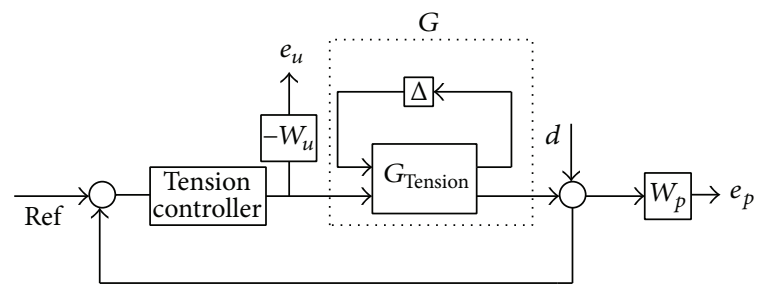

Figure 6: The block diagram of closed system with performance requirements.

\section{Robust Tension Controller Design}

This section considers the design of tension control system for 5-stand tandem mill. For this system, open loop and closedloop system interconnections are introduced and robust controllers are designed.

3.1. Requirements to Fulfill Design. The aim of robust tension controller design is to achieve and maintain the tension between stands in the presence of disturbances and uncertainties. The block diagram of the closed-loop system including the feedback and controller as well as the elements reflecting the model uncertainty and weighting functions related to performance requirements is shown in Figure 6.

In Figure 6, the rectangle with dashed line represents the transfer matrix $G$. Inside the rectangle is the nominal model of tension system and the uncertainty matrix $\Delta$ that includes the model uncertainties. The variables $d_{1}, d_{2}, d_{3}$, and $d_{4}$ are the disturbances on the system, at the system outputs. The output weighting performance vector $\left(e_{p}\right)$, control weighting performance $\left(e_{u}\right)$, and disturbances vector $(d)$ are defined as

$$
\begin{aligned}
e_{p} & =\left[e_{p 1}, e_{p 2}, e_{p 3}, e_{p 4}\right]^{\mathrm{T}}, \\
e_{u} & =\left[e_{u 1}, e_{u 2}, e_{u 3}, e_{u 4}\right]^{\mathrm{T}}, \\
d & =\left[d_{1}, d_{2}, d_{3}, d_{4}\right]^{\mathrm{T}} .
\end{aligned}
$$

In general, weighting functions would be used to meet the design specifications. Finding appropriate weighting functions is a crucial step in robust controller design and usually needs a few trials. The performance weighting function is 


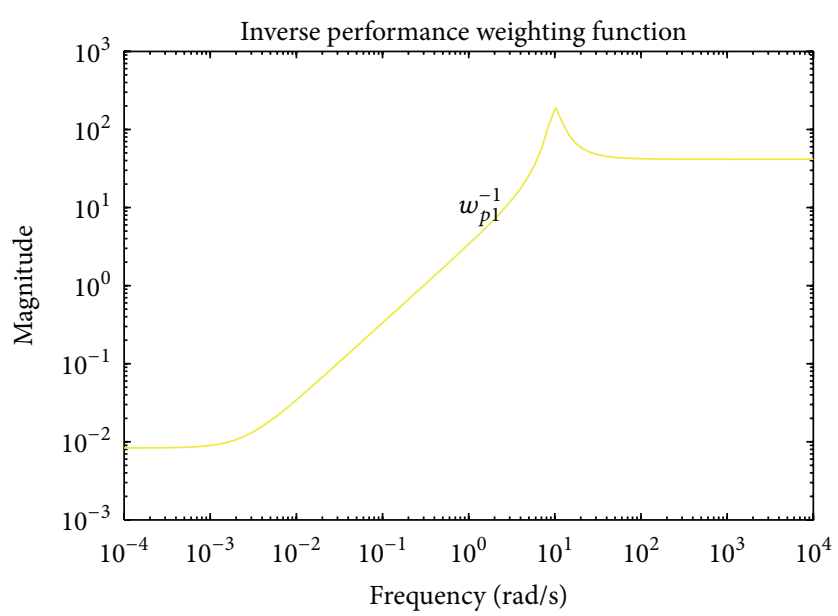

FIGURE 7: Singular values of $1 / w_{p}$.

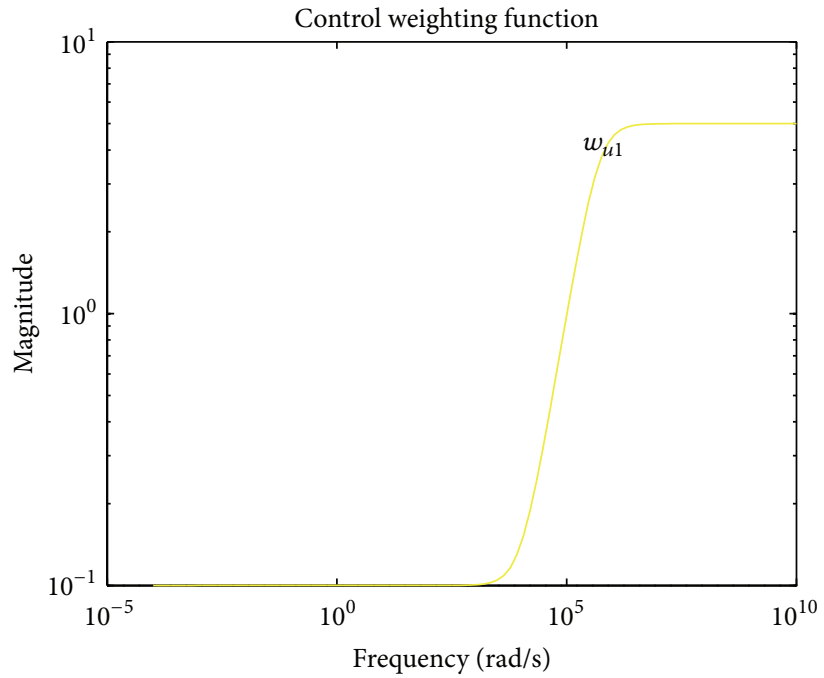

Figure 8: Singular values of $w_{u}$.

usually low-pass filter and control weighting function is highpass filter. Design experience will help in choosing weighting functions. In this design, the performance weighting function $w_{p}$ and the control weighting functions $w_{u}, W_{p}$, and $W_{u}$ are chosen as [13]

$$
\begin{gathered}
w_{p}=0.012 \frac{S^{2}+2.8 S+100}{0.5 S^{2}+4.0 S+0.01}, \\
w_{u}=5 \frac{S+10000}{S+500000}, \\
W_{p}=\left(\begin{array}{cccc}
w_{p 1} & 0 & 0 & 0 \\
0 & w_{p 2} & 0 & 0 \\
0 & 0 & w_{p 3} & 0 \\
0 & 0 & 0 & w_{p 4}
\end{array}\right),
\end{gathered}
$$

$$
W_{u}=\left(\begin{array}{cccc}
w_{u 1} & 0 & 0 & 0 \\
0 & w_{u 2} & 0 & 0 \\
0 & 0 & w_{u 3} & 0 \\
0 & 0 & 0 & w_{u 4}
\end{array}\right)
$$

The singular values of $1 / w_{p}$ over the frequency range $\left[10^{-4}, 10^{4}\right]$ are shown in Figure 7 . This weighting function shows that for low frequencies the closed-loop system (the nominal as well as perturbed system) attenuates the output disturbance in the ratio of 100 to 0.01 . In other words, the effect of a unit disturbance on the steady-state output should be of the order $10^{-2}$. This performance requirement becomes less stringent with increasing frequency.

Also, the singular values of $w_{u}$ over the frequency range $\left[10^{-4}, 10^{4}\right]$ are shown in Figure 8.

3.2. Open Loop and Closed-Loop System Interconnection. Before designing the tension controller, it is necessary to build 


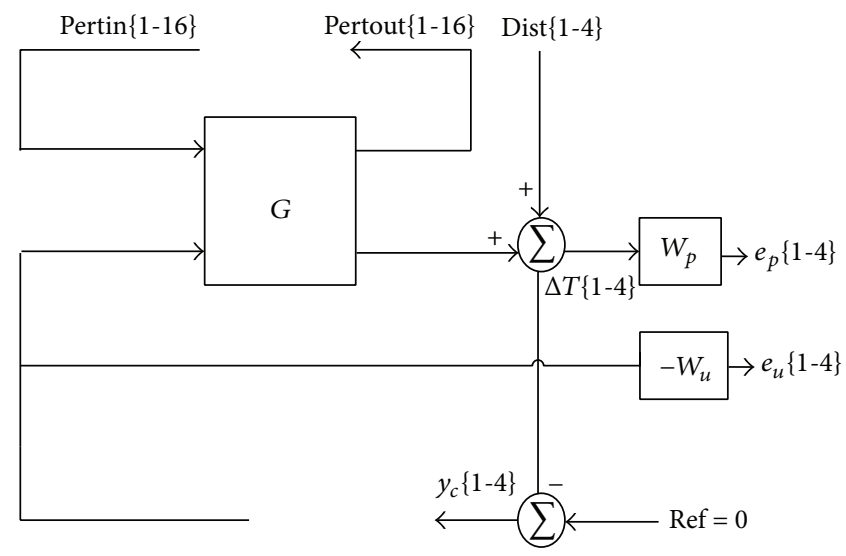

FIGURE 9: Structure of the open loop system.

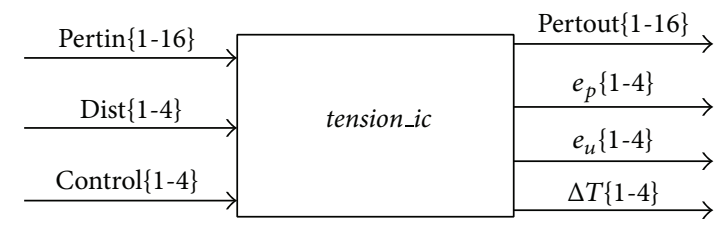

FIGURE 10: Block diagram of open loop system.

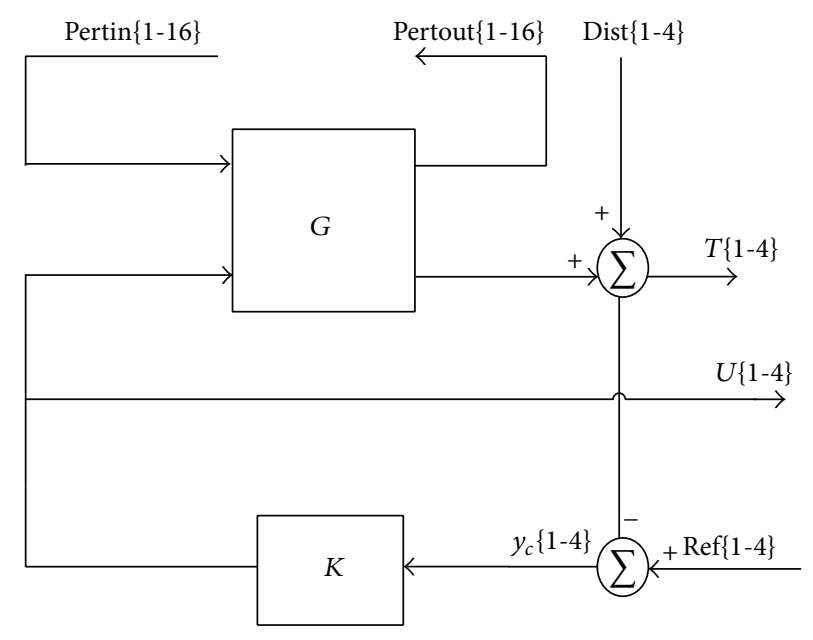

FIGURE 11: Structure of the closed-loop system.

interconnection for open-loop and closed-loop system. The structure of the open-loop system is represented in Figure 9. In Figure 10, tension_ic denotes the transfer function matrix of open loop system with 24 inputs and 28 outputs.

The simulation of closed-loop system with designed controllers is based on the structure shown in Figure 11. The weighting functions $w_{p}$ and $w_{u}$ are not included in the block diagram for obvious reasons.

3.3. $H_{\infty}$ Controller. The interconnection of nominal open loop system is denoted by hin_ic, as shown in Figure 12.
The suboptimal $H_{\infty}$ controller minimizes the infinite-norm of $F_{l}($ hin_ic, $k)$ overall stabilizing controller $K$. Note that $F_{l}($ hin_ic, $k)$ is the transfer function matrix of the nominal closed-loop system from the disturbances to the errors. To compute $H_{\infty}$ optimal controller for LTI plant, some conditions are satisfied by plant. Sometimes one of these conditions is not satisfied and the algorithm for computing does not work $[15,17]$. When this situation accrued, other robust control methods are used, although some tricks can be used to satisfy conditions. For example, adding or subtracting epsilon may solve the problem in these conditions. 


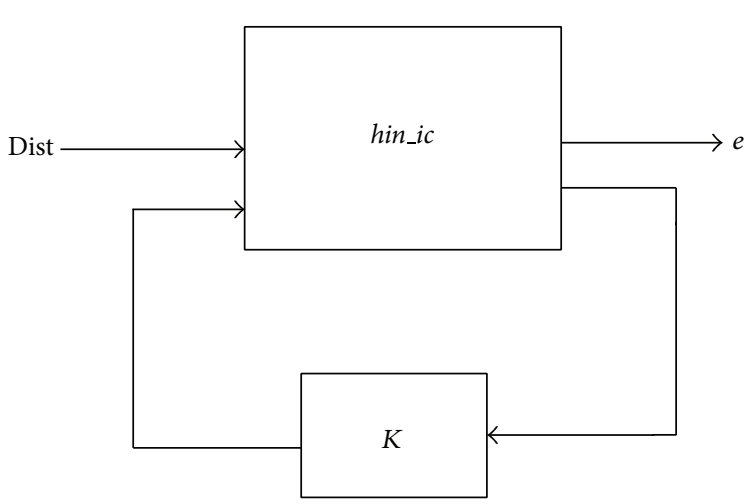

Figure 12: Closed-loop LFTs in $H_{\infty}$ design.
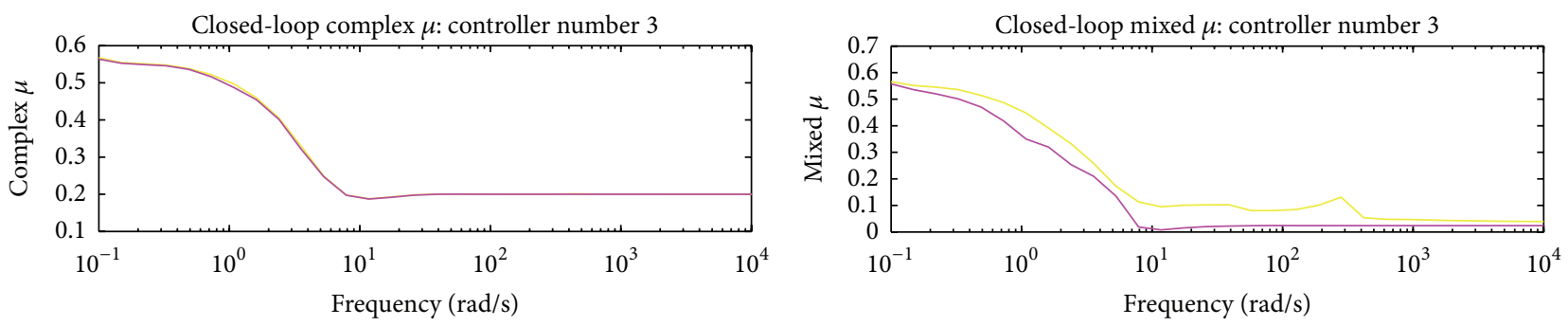

FIgURE 13: $\mu$ plot after third iteration.

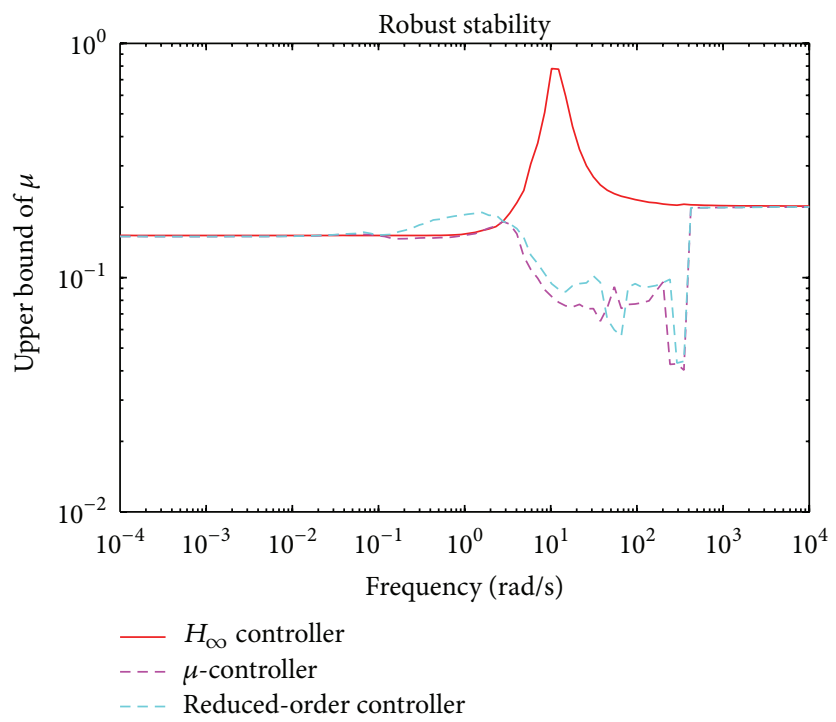

Figure 14: Comparison of robust stability for three controllers.

For this plant, $H_{\infty}$ controller is numerically computed and finally the obtained controller is of 20th order. The minimum value of $\gamma$ is 0.101 .

3.4. $\mu$ Controller. The $\mu$ synthesis is introduced by two iterative methods, $D-K$ and $\mu-K$ iteration. For this plant, $\mu$ synthesis is executed by the M-file dkit from the Robust Control Toolbox of Matlab, which automates the procedure by using $D-K$ iterations [15]. After the third iteration, the maximum value of $\mu$ is 0.567 , which indicates that the robust performance has been achieved. The final controller obtained is of 104th order. The $\mu$ plot of the closed-loop system is shown in Figure 13.

The order of this controller is 104 which makes it difficult in implementation. On the other hand, high order controllers will lead to high cost, difficult commissioning, poor reliability, and potential problems in maintenance. This is the weakness of $\mu$ controller in this design. Usually the order 


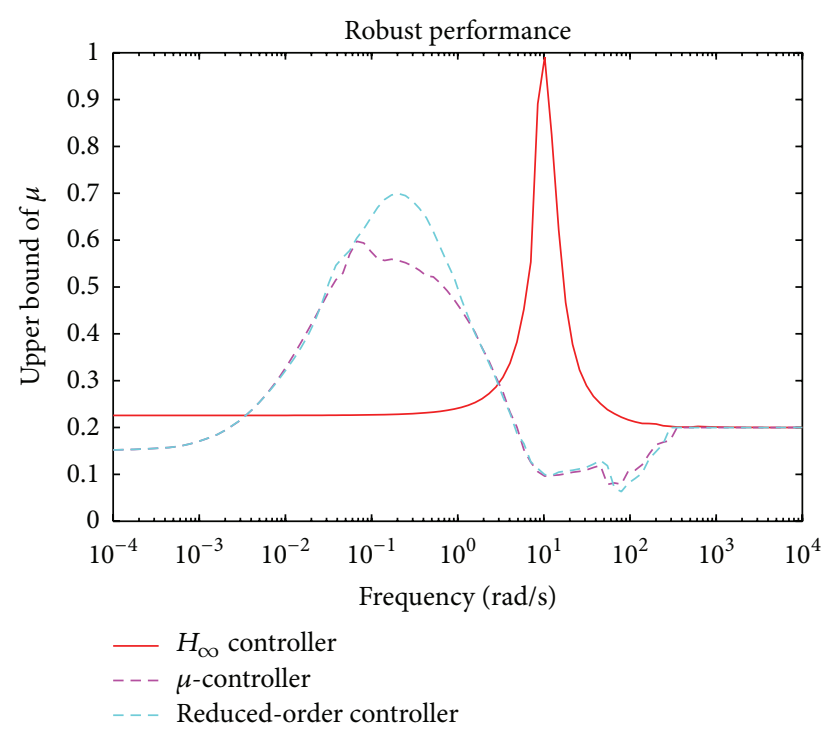

FIGURE 15: Comparison of robust performance for three controllers.
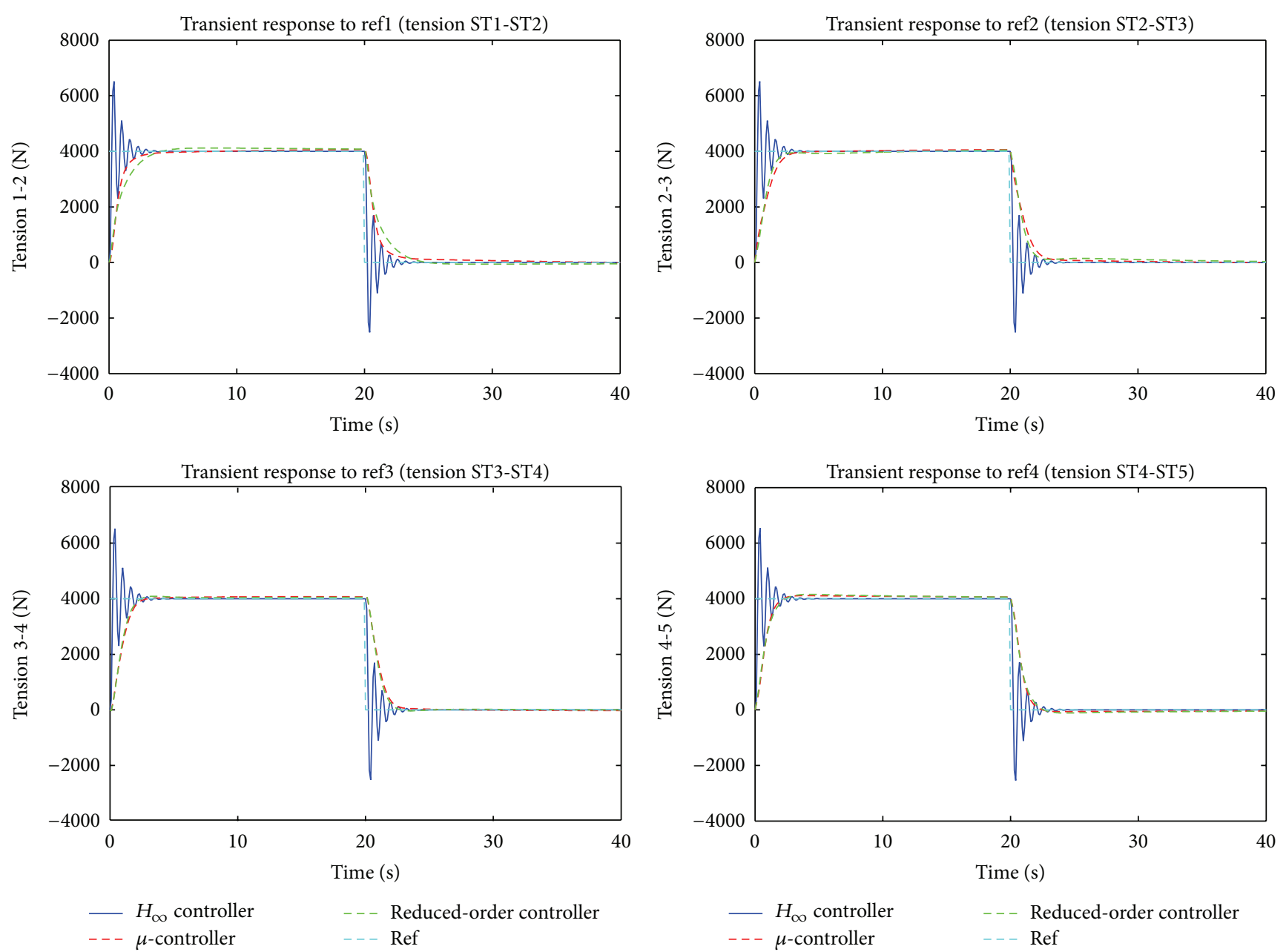

Figure 16: Comparison of transient response to reference input. 

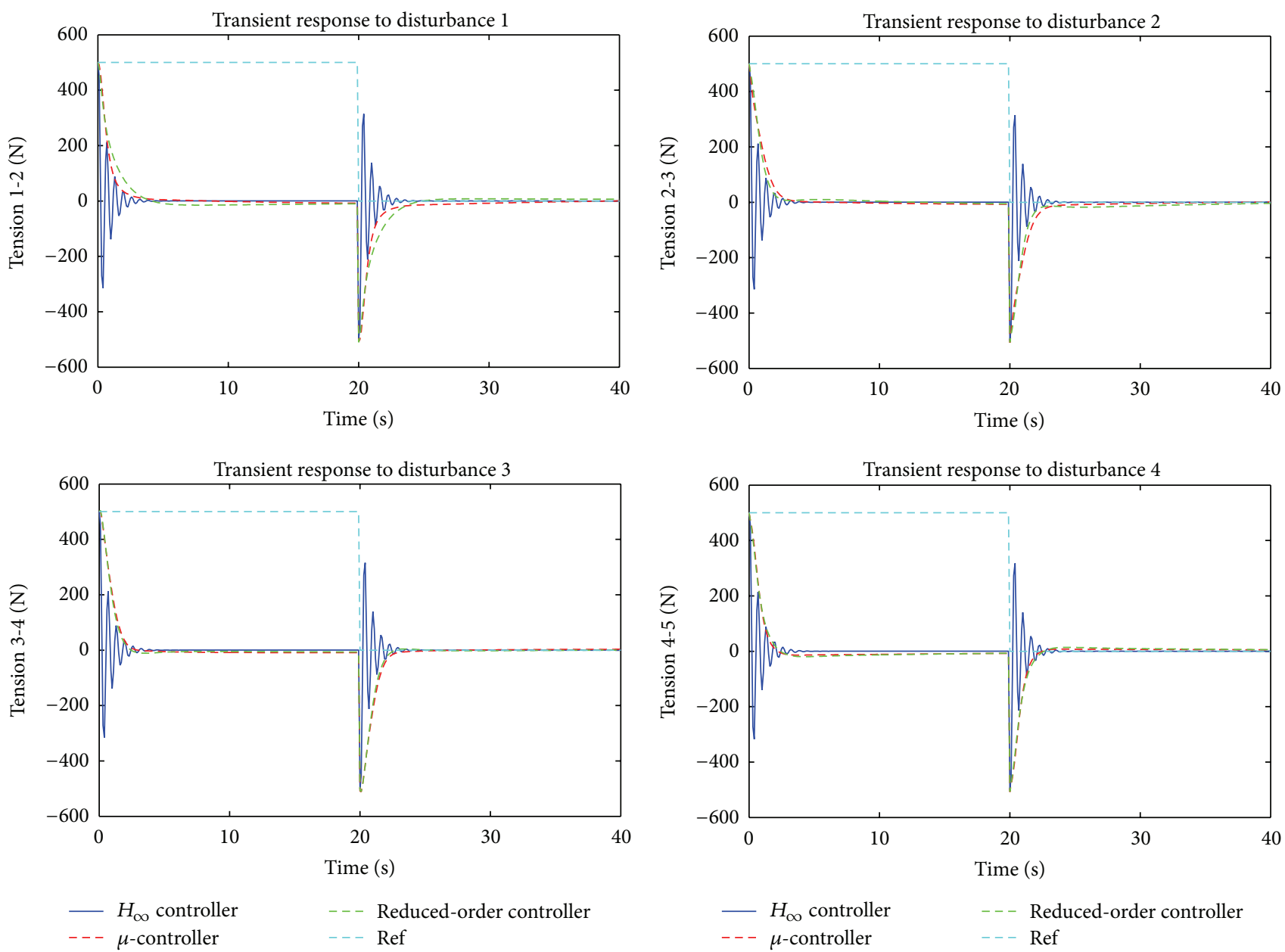

FIGURE 17: Comparison of transient response to disturbance signal.

can be reduced and reduction of the controller order may lead to deterioration of the closed-loop performance. Various methods may be used to reduce the order and in this case study, the Hankel-norm approximation is used. The reducedorder controller is equal to 13 that leads to a controller maintaining the robust stability and performance of the closed-loop system (matrices for reduced-order controller are presented in Appendix B).

\section{Simulation Results}

In the previous section, robust controllers for tension control system are introduced. It is intended here to compare the robust stability, robust performance, and time domain responses of the proposed controllers. Since the considered uncertainty is structured, verification of the robust stability and performance needs the frequency response in terms of $\mu$ values. On the other hand, controllers should be tested by means of $\mu$ analysis. The robust stability and performance do not maintain if the uncertainty is unstructured, which shows that the $\mu$ values give less conservative results if further information is known about the uncertainty.
4.1. Robust Stability. The frequency responses of the upper bound of $\mu$ for $H_{\infty}$ controller and $\mu$ and reduced-order controllers are shown in Figure 14. The maximum $\mu$ values for $H_{\infty}$ controller are equal to 0.7801 and the maximum $\mu$ values for $\mu$ and reduced-order controllers are 0.202 . Therefore, the robust stability of control systems is achieved and the systems with the $\mu$ controller and reduced-order controllers are characterized with better robust stability.

4.2. Robust Performance. The robust performance of control systems is plotted in Figure 15. The maximum $\mu$ values for $H_{\infty}$ controller are 0.99 , for $\mu$ controller 0.597 , and for reduced-order controller 0.69 which implies the robust $\mu$ controller and reduced-order controller achieve better robust performance than $H_{\infty}$ controller.

4.3. Time Domain Simulation. The transient responses of the closed-loop system to the reference input and the disturbance signal are shown in Figures 16 and 17, respectively. The $\mu$ and the reduced-order controllers give a better transient response with smaller overshoot than the $H_{\infty}$ controller. In summary, 
the $\mu$ and the reduced-order controllers lead to better tradeoff between the requirements in terms of transient response, disturbance rejection, and robustness.

\section{Conclusion}

In cold rolling, the strip tension should be controlled for better quality of products. For cold rolling with 5 stands, the state-space representation perturbed with parametric uncertainties is derived and, further, $H_{\infty}$ controller and $\mu$ controller based on robust control theory are designed. Tension control is obtained by means of the proposed robust controllers in the presence of uncertainties and disturbances. The order of the $\mu$ controller is large which requires the controller order reduction to preserve the closed-loop performance and robustness while making implementation of the controller easier and more reliable. The simulation results show that control systems achieve robust stability and robust performance. The comparison of the robust stability and robust performance for controllers as well as the comparison of the corresponding transient responses shows that the $\mu$ controller and its reduced-order are preferable, although the reduced-order controller would be usually preferred due to its lower order. It should be mentioned that in such important industrial process, most commissioning personnel have very little or no background in advanced control theory, especially in the theory and application of $H_{\infty}$ robust control techniques and are accustomed to single-input-single-output (SISO) proportional-integral (PI) type control loops. These simpler configurations are easy to tune at commissioning during actual operation.

\section{Appendices}

\section{A. The System Matrices}

Consider

$$
\begin{aligned}
& A=\left[\begin{array}{cccccccc}
-10 & 0 & 0 & 0 & 0 & 0 & 0 & 0 \\
44200 & 0 & 0 & 0 & 0 & 0 & 0 & 0 \\
0 & 0 & -10 & 0 & 0 & 0 & 0 & 0 \\
-44200 & 0 & 26000 & 0 & 0 & 0 & 0 & 0 \\
0 & 0 & 0 & 0 & -10 & 0 & 0 & 0 \\
0 & 0 & -26800 & 0 & 18600 & 0 & 0 & 0 \\
0 & 0 & 0 & 0 & 0 & 0 & -10 & 0 \\
0 & 0 & 0 & 0 & -18400 & 0 & 12200 & 0
\end{array}\right], \quad B_{2}=\left[\begin{array}{cccc}
10 & 0 & 0 & 0 \\
0 & 0 & 0 & 0 \\
0 & 10 & 0 & 0 \\
0 & 0 & 0 & 0 \\
0 & 0 & 10 & 0 \\
0 & 0 & 0 & 0 \\
0 & 0 & 0 & 10 \\
0 & 0 & 0 & 0
\end{array}\right],
\end{aligned}
$$

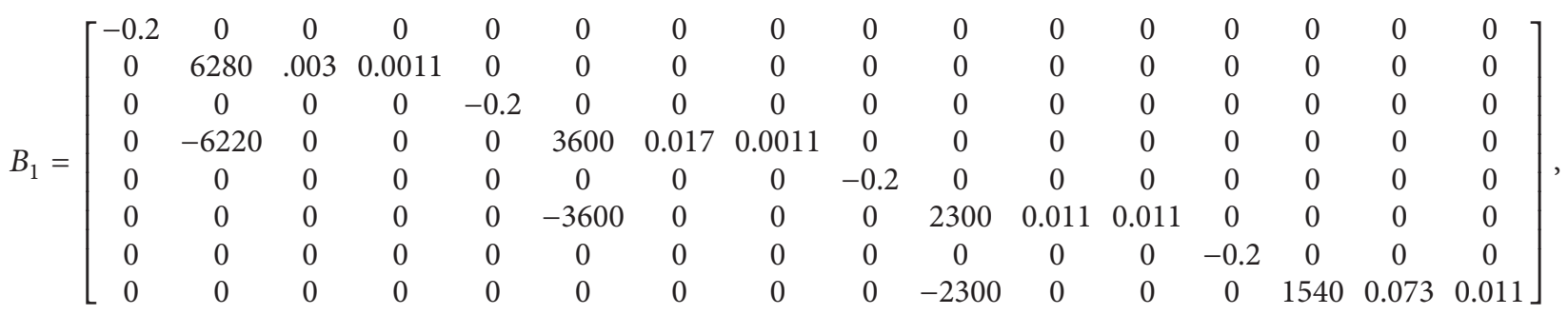

$$
\begin{aligned}
& C_{1}=\left[\begin{array}{cccccccc}
-10 & 0 & 0 & 0 & 0 & 0 & 0 & 0 \\
0.7 & 0 & 0 & 0 & 0 & 0 & 0 & 0 \\
147000 & 0 & 0 & 0 & 0 & 0 & 0 & 0 \\
199000 & 0 & 0 & 0 & 0 & 0 & 0 & 0 \\
0 & 0 & -10 & 0 & 0 & 0 & 0 & 0 \\
0 & 0 & 0.75 & 0 & 0 & 0 & 0 & 0 \\
-257000 & 0 & 157000 & 0 & 0 & 0 & 0 & 0 \\
-197000 & 0 & 120000 & 0 & 0 & 0 & 0 & 0 \\
0 & 0 & 0 & 0 & -10 & 0 & 0 & 0 \\
0 & 0 & 0 & 0 & 0.8 & 0 & 0 & 0 \\
0 & 0 & -242000 & 0 & 168000 & 0 & 0 & 0 \\
0 & 0 & -1210000 & 0 & 84000 & 0 & 0 & 0 \\
0 & 0 & 0 & 0 & 0 & 0 & -10 & 0 \\
0 & 0 & 0 & 0 & 0 & 0 & 0.8 & 0 \\
0 & 0 & 0 & 0 & -253000 & 0 & 168000 & 0 \\
0 & 0 & 0 & 0 & -84000 & 0 & 55000 & 0 \\
0 & & & 0 & 0 & & 0 & 0
\end{array}\right], \quad C_{2}=\left[\begin{array}{ccccccccc}
0 & 1 & 0 & 0 & 0 & 0 & 0 & 0 \\
0 & 0 & 0 & 1 & 0 & 0 & 0 & 0 \\
0 & 0 & 0 & 0 & 0 & 1 & 0 & 0 \\
0 & 0 & 0 & 0 & 0 & 0 & 0 & 1
\end{array}\right],
\end{aligned}
$$




$$
D_{11}=\left[\begin{array}{cccccccccccccccc}
-0.2 & 0 & 0 & 0 & 0 & 0 & 0 & 0 & 0 & 0 & 0 & 0 & 0 & 0 & 0 & 0 \\
0 & 0 & 0 & 0 & 0 & 0 & 0 & 0 & 0 & 0 & 0 & 0 & 0 & 0 & 0 & 0 \\
0 & 21000 & 0 & 0 & 0 & 0 & 0 & 0 & 0 & 0 & 0 & 0 & 0 & 0 & 0 & 0 \\
0 & 28300 & 0.135 & 0 & 0 & 0 & 0 & 0 & 0 & 0 & 0 & 0 & 0 & 0 & 0 & 0 \\
0 & 0 & 0 & 0 & -0.2 & 0 & 0 & 0 & 0 & 0 & 0 & 0 & 0 & 0 & 0 & 0 \\
0 & 0 & 0 & 0 & 0 & 0 & 0 & 0 & 0 & 0 & 0 & 0 & 0 & 0 & 0 & 0 \\
0 & 36700 & 0 & 0 & 0 & 21000 & 0 & 0 & 0 & 0 & 0 & 0 & 0 & 0 & 0 & 0 \\
0 & -28200 & 0 & 0 & 0 & 16700 & 0.077 & 0 & 0 & 0 & 0 & 0 & 0 & 0 & 0 & 0 \\
0 & 0 & 0 & 0 & 0 & 0 & 0 & 0 & -0.2 & 0 & 0 & 0 & 0 & 0 & 0 & 0 \\
0 & 0 & 0 & 0 & 0 & 0 & 0 & 0 & 0 & 0 & 0 & 0 & 0 & 0 & 0 & 0 \\
0 & 0 & 0 & 0 & 0 & -32300 & 0 & 0 & 0 & 21000 & 0 & 0 & 0 & 0 & 0 & 0 \\
0 & 0 & 0 & 0 & 0 & -16100 & 0 & 0.05 & 10500 & 0 & 0 & 0 & 0 & 0 & 0 & 0 \\
0 & 0 & 0 & 0 & 0 & 0 & 0 & 0 & 0 & 0 & 0 & 0 & -0.2 & 0 & 0 & 0 \\
0 & 0 & 0 & 0 & 0 & 0 & 0 & 0 & 0 & 0 & 0 & 0 & 0 & 0 & 0 & 0 \\
0 & 0 & 0 & 0 & 0 & 0 & 0 & 0 & 0 & -31700 & 0 & 0 & 0 & 21000 & 0 & 0 \\
0 & 0 & 0 & 0 & 0 & 0 & 0 & 0 & 0 & -10400 & 0 & 0 & 0 & 6930 & 0.033 & 0
\end{array}\right],
$$

\section{B. Matrices for Reduced-Order Controller}

Consider

$$
\mathrm{ak}=\left[\begin{array}{ccccccccccccc}
-135.34 & 96.71 & 24.55 & -16.74 & -1.22 & 1.55 & -0.48 & 2.99 & 1.09 & 0.14 & -0.08 & -0.19 & 0.11 \\
0 & -27.34 & 5.23 & 16.42 & 1.47 & -0.68 & 0.4 & -1.36 & -0.65 & 0.005 & 0.07 & 0.1 & -0.048 \\
0 & -28.72 & -27.7 & 0.3 & -12.67 & -0.21 & 0.05 & -0.65 & 0.03 & -0.1 & 0.09 & 0.02 & 0.04 \\
0 & 0 & 0 & -6.11 & -1.84 & 0.18 & -0.29 & 0.31 & 0.42 & -0.09 & -0.02 & -0.02 & 0.018 \\
0 & 0 & 0 & 1.45 & -6.62 & -0.08 & 0.19 & -0.11 & -0.06 & -0.02 & 0 & 0.003 & 0 \\
0 & 0 & 0 & 0 & 0 & -0.008 & 0.06 & -0.02 & -0.008 & -0.001 & 0 & 0.002 & 0.001 \\
0 & 0 & 0 & 0 & 0 & -0.06 & -0.004 & 0.008 & 0.008 & -0.002 & 0 & 0 & 0.001 \\
0 & 0 & 0 & 0 & 0 & 0 & 0 & -0.02 & 0.02 & -0.004 & -0.001 & 0 & 0 \\
0 & 0 & 0 & 0 & 0 & 0 & 0 & -0.04 & -0.008 & 0.002 & -0.003 & 0 & 0 \\
0 & 0 & 0 & 0 & 0 & 0 & 0 & 0 & 0 & -0.003 & 0 & 0 & 0 \\
0 & 0 & 0 & 0 & 0 & 0 & 0 & 0 & 0 & 0 & -0.002 & 0 & 0 \\
0 & 0 & 0 & 0 & 0 & 0 & 0 & 0 & 0 & 0 & 0 & -0.002 & 0 \\
0 & 0 & 0 & 0 & 0 & 0 & 0 & 0 & 0 & 0 & 0 & 0 & -0.002
\end{array}\right] \text {, }
$$




$$
\begin{aligned}
& \mathrm{bk}=\left[\begin{array}{cccc}
0.15 & 0.08 & 0.02 & 0.04 \\
-0.04 & -0.03 & -0.01 & -0.01 \\
-0.05 & -0.002 & -0.02 & 0 \\
-0.008 & 0.01 & 0.01 & 0.01 \\
-0.006 & 0.008 & 0.003 & -0.01 \\
0 & 0 & 0 & 0 \\
0 & 0 & 0 & 0 \\
-0.001 & 0 & 0 & 0 \\
0 & 0 & 0 & 0 \\
0 & 0 & 0 & 0 \\
0.001 & 0 & 0 & 0 \\
0 & 0 & 0 & -0.001 \\
0 & 0 & 0 & -0.001
\end{array}\right] \text {, } \\
& \mathrm{ck}=\left[\begin{array}{ccccccccccccc}
-0.001 & -0.006 & 0 & 0.001 & -0.001 & 0 & 0 & 0 & 0 & 0 & 0 & 0 & 0 \\
0.06 & -0.02 & -0.009 & 0.001 & 0.007 & 0 & 0 & 0 & 0 & 0 & 0 & 0.001 & 0 \\
0.009 & -0.04 & -0.03 & 0.01 & 0 & 0 & 0 & 0 & 0 & 0 & 0.001 & 0 & 0.001 \\
0.13 & -0.08 & -0.05 & 0.01 & 0 & 0 & 0.001 & -0.002 & 0 & 0 & 0.001 & -0.001 & -0.001
\end{array}\right] \text {, } \\
& \mathrm{dk}=\left[\begin{array}{cccc}
0 & 0 & 0 & 0 \\
0 & 0 & 0 & 0 \\
0 & 0 & 0 & 0 \\
0 & 0 & 0 & 0
\end{array}\right]
\end{aligned}
$$

\section{Abbreviations}

$V: \quad$ Work roll linear velocity

$U_{v}$ : Speed actuator input

$\tau_{v}: \quad$ Speed actuator time constant

$V_{\text {in }}$ : Input strip velocity

$V_{\text {out }}$ : Output strip velocity

$h_{\text {in }}$ : Stand input thickness

$h_{\text {out }}$ : Stand output thickness

$f: \quad$ Forward slip ratio

$\varphi$ : Backward slip ratio

$E$ : Young's modulus

$B$ : Width of strip

$H_{i+1}$ : Strip thickness between stand $i$ and stand $i+1$

$L: \quad$ Length between adjacent stands

$T_{i, i+1}$ : Strip tension between stand $i$ and stand $i+1$.

\section{Conflict of Interests}

The authors declare that there is no conflict of interests regarding the publication of this paper.

\section{References}

[1] W. S. Levine, Control System Applications, Taylor \& Francis, Boca Raton, Fla, USA, 2011.

[2] J. Pittner, N. S. Samaras, and M. A. Simaan, "A simple rolling mill model with linear quadratic optimal controller," in Proceedings of the 37th IAS Annual Meeting and World Conference on Industrial Applications of Electrical Energy, pp. 142-149, October 2002 .
[3] H. R. Koofigar, F. Sheikholeslam, and S. Hosseinnia, "Unified gauge-tension control in cold rolling mills: a robust regulation technique," International Journal of Precision Engineering and Manufacturing, vol. 12, no. 3, pp. 393-403, 2011.

[4] E. J. M. Geddes and I. Postlethwaite, "Improvements in product quality in tandem cold rolling using robust multivariable control," IEEE Transactions on Control Systems Technology, vol. 6, no. 2, pp. 257-269, 1998.

[5] E. J. M. Geddes and I. Postlethwaite, "Multivariable control of a high performance tandem cold rolling mill," in Proceedings of the International Conference on Control (CONTROL '94), vol. 1, pp. 202-207, Coventry, UK, March 1994.

[6] E. Arinton, S. Caraman, and J. Korbicz, "Neural networks for modelling and fault detection of the inter-stand strip tension of a cold tandem mill," Control Engineering Practice, vol. 20, no. 7, pp. 684-694, 2012.

[7] K. M. Takami, J. Mahmoudi, and E. Dahlquist, "Adaptive control of cold rolling system in electrical strips production system with online-offline predictors," International Journal of Advanced Manufacturing Technology, vol. 50, no. 9-12, pp. 917-930, 2010.

[8] G. Pin, V. Francesconi, F. A. Cuzzola, and T. Parisini, "Adaptive task-space metal strip-flatness control in cold multi-roll mill stands," Journal of Process Control, vol. 23, no. 2, pp. 108-119, 2013.

[9] J. Pittner and M. A. Simaan, "An optimal control method for improvement in tandem cold metal rolling," in Proceedings of the IEEE 42nd Annual Meeting Industry Applications Conference (IAS '07), pp. 382-389, September 2007.

[10] J. R. Pittner, Pointwise linear quadratic optimal control of a tandem cold rolling mill [Ph.D. thesis], School of Engineering, University of Pittsburgh, 2006.

[11] L. E. Zárate, "Predictive model for the cold rolling process through sensitivity factors via neural networks," Journal of the 
Brazilian Society of Mechanical Sciences and Engineering, vol. 28, no. 1, pp. 111-117, 2006.

[12] S.-H. Song and S.-K. Sul, "A new tension controller for continuous strip processing line," IEEE Transactions on Industry Applications, vol. 36, no. 2, pp. 633-639, 2000.

[13] X. Zhang and Q. Zhang, "Robust control of strip tension for tandem cold rolling mill," in Proceedings of the 30th Chinese Control Conference (CCC '11), pp. 2390-2393, Yantai, China, July 2011.

[14] J. Pittner and M. A. Simaan, Tandem Cold Metal Rolling Mill Control Using Practical Advanced Methods, Springer, London, UK, 2011.

[15] D. Gu, P. H. Petkov, and M. Konstantinov, Robust Control Design with MATLAB, Springer, London, UK, 2005.

[16] Z. Xiaofeng and Z. Qingdong, "Robust control of strip thickness for cold rolling mill," in Informatics in Control, Automation and Robotics, vol. 133 of Lecture Notes in Electrical Engineering, pp. 777-785, Springer, Berlin, Germany, 2012.

[17] K. Zohu and J. C. Doyle, Essentials of Robust Control, Prentice Hall, 1997. 

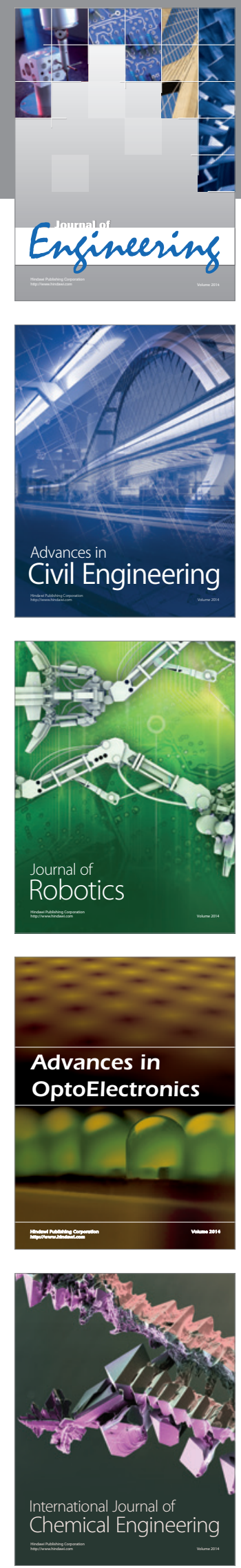

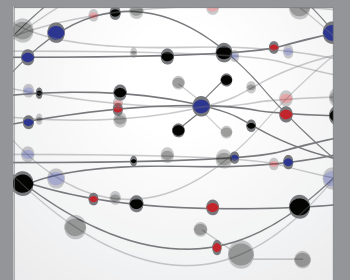

The Scientific World Journal
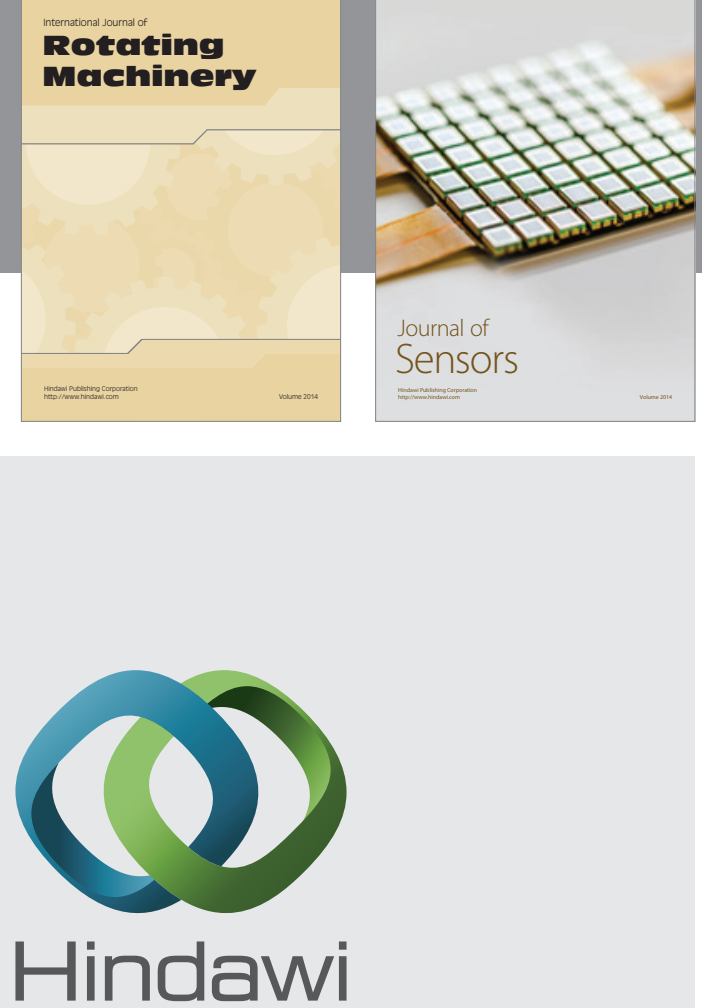

Submit your manuscripts at http://www.hindawi.com
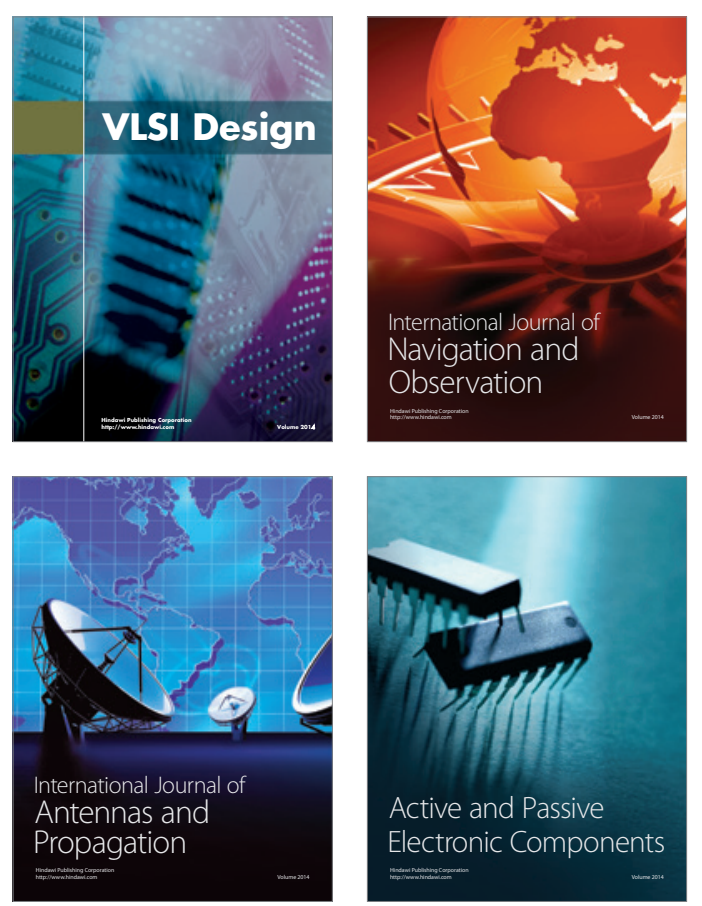
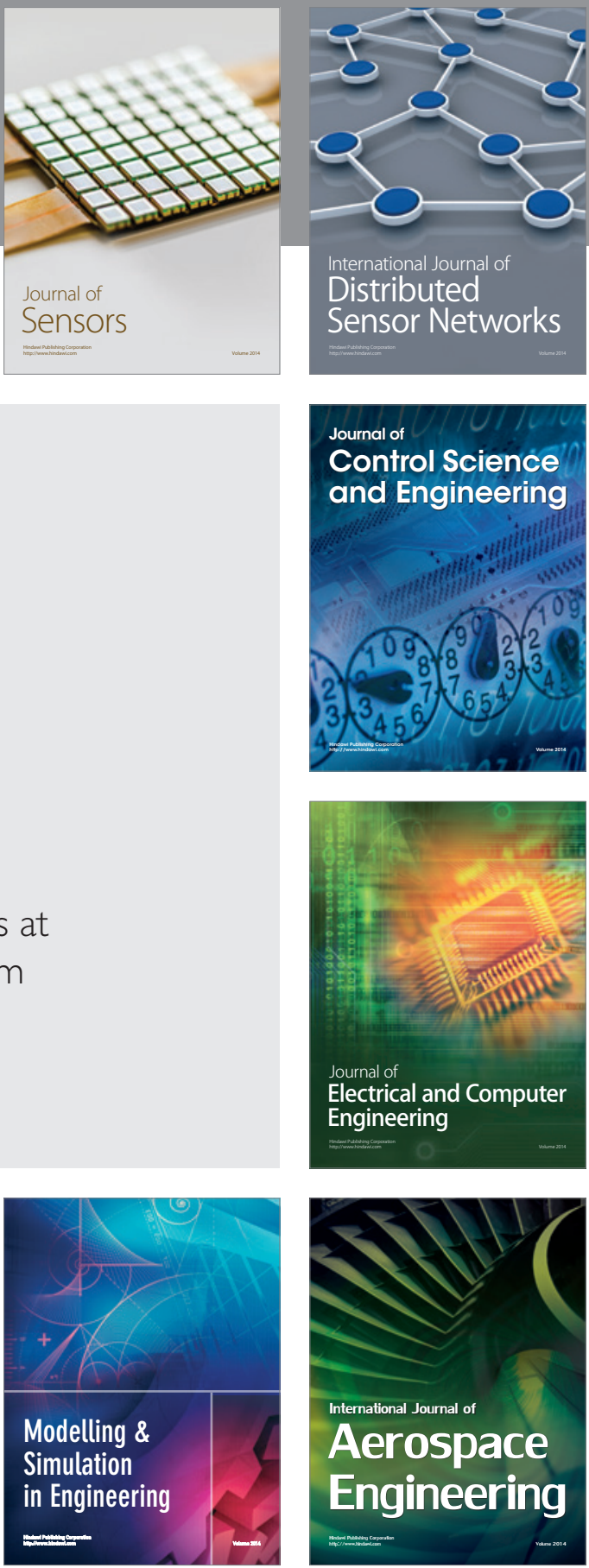

Journal of

Control Science

and Engineering
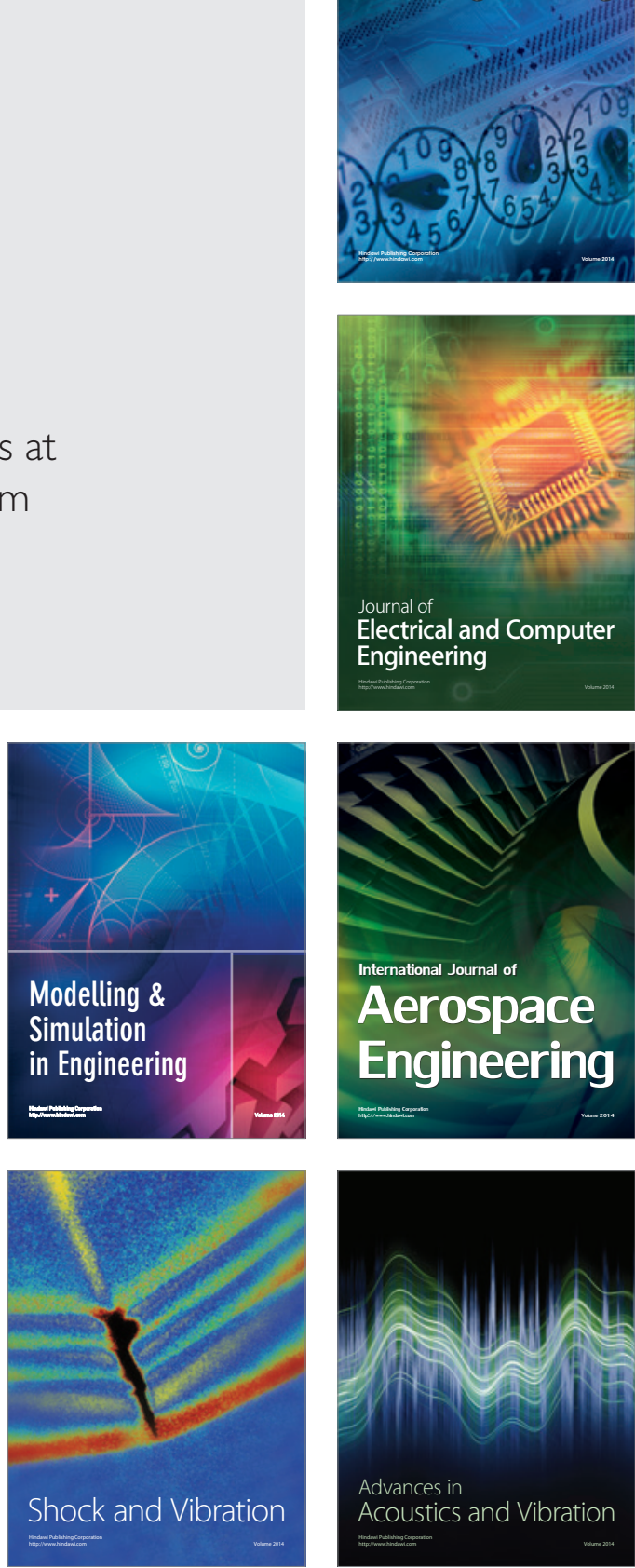